\title{
Prevalence of anthelmintic resistance in gastrointestinal nematodes of sheep and goats in Norway
}

\author{
Atle V. Meling Domke - Christophe Chartier • \\ Bjørn Gjerde • Johan Höglund • Nils Leine • \\ Synnøve Vatn • Snorre Stuen
}

Received: 2 October 2011 / Accepted: 5 January 2012 /Published online: 31 January 2012

(C) The Author(s) 2012. This article is published with open access at Springerlink.com

\begin{abstract}
In the period of 2008-2009, the efficacies of the benzimidazole (BZ) albendazole and the macrocyclic lactone (ML) ivermectin against gastrointestinal nematodes (GIN) of small ruminants were evaluated by means of the fecal egg count reduction (FECR) test and by post-treatment identification of surviving third stage (L3) larvae after coproculture. Sheep $(n=28)$ and goat $(n=28)$ flocks from three areas of Norway were randomly selected to assess the prevalence of anthelmintic resistance (AR), whereas only lambs from non-randomly selected sheep flocks $(n=32)$ with a farm management that could select for AR were investigated
\end{abstract}

A. V. M. Domke $(\bowtie) \cdot$ S. Stuen

Norwegian School of Veterinary Science,

Sandnes, Norway

e-mail: Atle.Domke@nvh.no

C. Chartier

LUNAM Université, ONIRIS, Nantes-Atlantic College

of Veterinary Medicine, Food Science and Engineering,

UMR 1300 BIOEPAR,

Nantes, France

B. Gjerde

Norwegian School of Veterinary Science,

Oslo, Norway

J. Höglund

Department of Biomedical Sciences and Veterinary Public Health,

Section for Parasitology, Swedish University of Agricultural

Sciences,

Uppsala, Sweden

N. Leine

Norwegian Goat Health Service,

Oslo, Norway

S. Vatn

Norwegian Sheep Health Service, Animalia,

Oslo, Norway the second year. Only flocks with a mean excretion of nematode eggs per gram feces (EPG) $\geq 150$ at time of treatment were included in the survey. In total, $48(80 \%)$ and 13 (46.4\%) of the selected sheep and goat flocks, respectively, fulfilled the inclusion criteria. The proportions of flocks classified as resistant (i.e., FECR $<95 \%$ and with a lower $95 \%$ confidence interval of $<90 \%$ ) for the BZ drug albendazole were $10.5 \%$ and $31.0 \%$ in the randomly and nonrandomly selected sheep flocks, respectively. When restricting the area to Rogaland County, eight flocks out of ten (80\%) non-randomly selected sheep flocks showed BZ resistance. The efficacy of ML was $100 \%$ in all surveyed sheep and goat flocks. In post-treatment coprocultures from the non-randomly selected flocks, the main nematode genera were Teladorsagia/Trichostrongylus in five flocks, Haemonchus in two flocks, and a mixture of these genera in the remaining two flocks. In the goat flocks, the pretreatment infection levels of GIN were low compared to what was found in the sheep flocks. Still, in one flock, AR against BZ in Teladorsagia/Trichostrongylus was found. New strategies and recommendations to face the emerging AR situation in Rogaland County in order to limit the spread of resistant nematodes within and into other areas are urgently needed.

\section{Introduction}

Anthelmintic resistance (AR) has become a global problem in the small ruminant industry during the last three decades, with the first cases emerging from the southern hemisphere (Waller 1994). In Europe, resistance to benzimidazole (BZ) has been found in up to $80 \%$ of flocks and AR to two, or even all three, major groups of anthelmintics has been recorded (Bartley et al. 2003; Bauer 2001; Cernanska et al. 
2006; Coles 1997; Höglund et al. 2009; Maingi et al. 1996a; Sargison et al. 2001; Traversa et al. 2007).

In some regions, AR is of greater concern in goats than in sheep. For example, in France, prevalence surveys in dairy goat flocks against $\mathrm{BZ}$ compounds have indicated that the proportion of flocks exhibiting resistant nematodes ranges from $80 \%$ to $100 \%$ (Chartier et al. 1998; Chartier et al. 2001). In addition, multiple resistances to levamisole (LEV) have been detected (Paraud et al. 2009). Since goats and sheep may share the same parasite species, mixed grazing of sheep and goats has been evoked as a possible risk factor for the spread and emergence of AR (Coles et al. 1996). Moreover, goats have frequently been underdosed, since they, in general, are dosed like sheep or cattle, although they actually need a higher dose rate, particularly as regards BZ and macrocyclic lactone (ML) (Bogan et al. 1987; Chartier et al. 1999; Hennessy et al. 1993; Hennessy and Alvinerie 2002; Sangster et al. 1993; Short et al. 1987).

A recent study performed on anthelmintic worm control practices in Norwegian sheep and goat flocks has indicated the occurrence of underdosing, a lack of anthelmintic class rotation and, in some breeding areas, a high drench frequency, which alone or in combination, are likely to increase the risk for AR (Domke et al. 2011). So far no systematic surveys have been performed, and only sporadic cases of BZ resistance have been reported in Norwegian sheep flocks (Ulvund et al. 1994; Vatn et al. 2005), whereas no study has been made in goats.

The aim of this nationwide study was to investigate the prevalence of AR for the two classes of anthelmintics used as dewormers in Norwegian sheep and goat flocks and to identify the nematode genera involved. In a second step, the survey was focused on sheep flocks where factors likely to promote the emergence of AR had been identified.

\section{Materials and methods}

\section{Selection of farms}

Altogether, 60 sheep farms and 28 dairy goat farms were selected to participate in the survey. The farms were located in eight counties distributed in three different climatic and geographical regions in Norway (Fig. 1).

The survey was divided into two successive steps. In 2008, lambs from 28 sheep flocks and adults from 15 dairy goat flocks were randomly selected among Norwegian small ruminant flocks. The only selection criteria were that they had more than 25 winter-feed ewes or dairy goats and agreed to participate.

In 2009, following a study on worm control practices (Domke et al. 2011), lambs from 32 additional sheep flocks defined as having a risk for developing AR, were selected on the basis of one or more of the following criteria: (a) $>4$ annual anthelmintic treatments of the lambs during the grazing

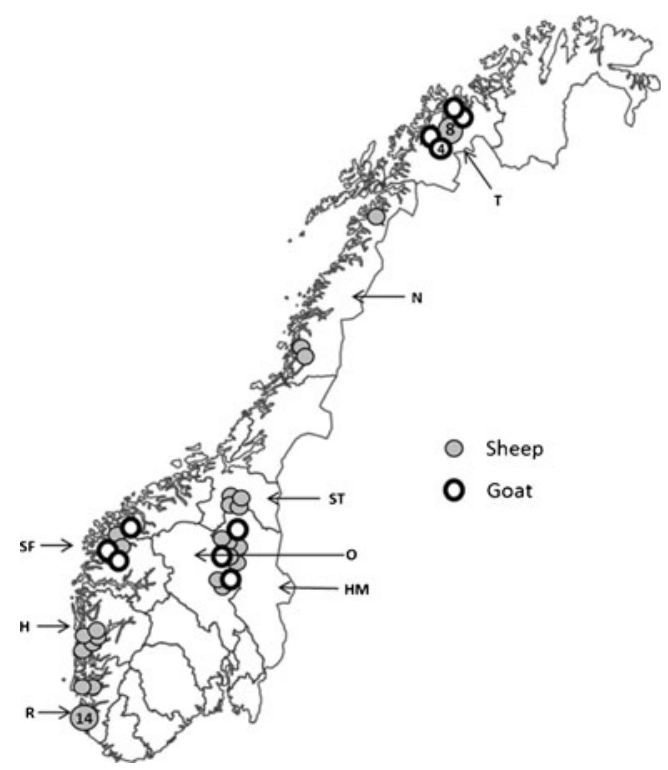

Fig. 1 Map of Norway showing the counties and location of the sampled sheep and goat flocks in the survey ( $H$ Hordaland, $H M$ Hedmark, $N$ Nordland, $O$ Oppland, $R$ Rogaland, SF Sogn- og Fjordane, ST Sør-Trøndelag, $T$ Troms)

period, (b) application of the dose-and-move strategy during summer grazing, or (c) intensive use of home grazing pasture (stocking rate above six sheep/ha), often in combination with frequent deworming. Frequent deworming, underdosing, practicing dose-and-move and lack of anthelmintic class change over years were regarded as the main reasons for the AR situation in Denmark (Maingi et al. 1996a, b) and were adopted as possible risk factors also for Norwegian sheep flocks.

Regarding goats, the selection of 13 additional dairy goat flocks in 2009 was based on the same criteria as the year before, but only young females (first grazing season/nonlactating) instead of adults were surveyed in order to increase the likelihood of sampling animals with a higher nematode egg excretion (Hoste et al. 2002).

$\mathrm{BZ}$ and ML are the only licensed anthelmintic classes for use in sheep in Norway, and BZ is by far the major anthelmintic class used. For goats, only fenbendazole (Panacur vet, Intervet and Curaverm vet, Jan F Andersen) is licensed; other BZs and MLs have been commonly used off-license (Domke et al. 2011). Morantel (Exhelm vet, Pfizer) was used in sheep until 2006, whereas levamisol (Levoripercol vet. injection) was licensed in Norway from 1981 till 1993 (Torjusen, Norwegian Medicines Agency, personal communication). BZ and ML were thus the most likely anthelmintic classes against which resistance may have developed.

Procedure

The recommendations by the World Association for the Advancement of the Veterinary Parasitology (Coles et al. 
1992, 2006) regarding detection of anthelmintic resistance in nematodes were followed. Accordingly, the fecal egg count reduction test (FECRT) was performed both years in the period from August until October. Before the start of the study, the nematode egg excretions in feces in most of the selected flocks were determined with 15 individual fecal samples to ensure a level equal to or above 150 eggs per gram feces (EPG) in more than ten first grazing season animals.

On each farm, 30 lambs or 30 adult/young female dairy goats were randomly selected and distributed into 2 treatment groups of 15 animals each. None of the tested animals had received any anthelmintics during the preceding 6 weeks. The three heaviest-looking lambs in each group were weighed for calculation of the specific anthelmintic dose rate in the flock. In the goat flocks, only visual estimation of weight of the three heaviest-looking goats was used as there was no scale available.

At day 0 , a fecal sample was taken from the rectum of each animal before all animals in group 1 were given the BZ drug albendazole (Valbazen vet ${ }^{\circledR}$, Pfizer), whereas those in group 2 received the ML ivermectin (Ivomec vet ${ }^{\circledR}$, Merial). Both drugs were administrated orally by a veterinarian using a calibrated drench gun. In sheep, albendazole and ivermectin were given at the recommended dose rate of 3.8 and $0.2 \mathrm{mg} / \mathrm{kg}$ body weight, respectively. For the dairy goats, both drugs were given at a dose rate 1.5 times higher than that for sheep, taking into account the species differences in bioavailability (Hennessy and Alvinerie 2002; Hennessy et al. 1993). On day 14 post-treatment, individual fecal samples were taken rectally from treated animals.

All fecal samples were sent by mail to the Norwegian School of Veterinary Science, Sandnes, in airtight plastic bags to slow down the egg development and hatching. A modified McMaster technique with saturated $\mathrm{NaCl}$ solution as the flotation fluid and a detection level of 50 gastrointestinal nematode (GIN) eggs per gram feces was performed on all individual fecal samples (Coles et al. 2006). Pooled coprocultures obtained from the pre- and post-treatment fecal samples were prepared and incubated at $22-25^{\circ} \mathrm{C}$ in moist conditions for 9-12 days to obtain infective third stage larvae (L3) that were harvested using the Baermann technique. The GIN L3 in the coprocultures was then differentiated according to keys in Ministry of Agriculture, Fisheries and Food (1986) to the generic level as Teladorsagia/Trichostrongylus, Haemonchus, Cooperia, or Oesophagostomum/Chabertia. Larval composition was determined through microscopical examination of 100 randomly selected L3.

\section{Statistical analysis}

The formula, FECR $=(1 / \mathrm{n}) \sum\left(100 \times\left(1-\left[\mathrm{T}_{\mathrm{i} 2} / \mathrm{T}_{\mathrm{i} 1}\right]\right)\right)$, where $T_{\mathrm{i} 2}$ is post-treatment and $T_{\mathrm{i} 1}$ is pre-treatment EPG in host $i$ from a total of $n$ hosts was used for calculation of post-treatment
EPG reduction and the associated 95\% confidence intervals (CI) by using Resiver 1.0 (Cabaret and Berrag 2004; http:// wcentre.tours.inra.fr/sfpar/stat.htm), where each animal served as its own control (Cabaret and Berrag 2004). For the calculation of arithmetic mean EPG, standard deviations ( \pm SD) and Mann-Whitney test and Excel 2003 (Microsoft Inc.) were used. Resistance to an anthelmintic class (R) was considered to be present if the percentage reduction in FEC after treatment was less than $95 \%$, and the lower limit of the $95 \%$ confidence interval was less than $90 \%$. If only one of the two criteria was met, resistance was suspected (SR) to be present (Coles et al. 1992).

\section{Results}

Pre-treatment samples

In nine of the 28 sheep flocks surveyed in 2008 , as well as in three of the 32 flocks examined in 2009, a mean EPG $\geq 150$ was not present. In total, $48(80 \%)$ of the sheep flocks fulfilled the criteria regarding nematode egg excretion at the time of treatment (Table 1).

In 2008, a mean pre-treatment EPG of $117( \pm 119)$ was found in adult goats, and only five (33.3\%) of the 15 flocks passed the criteria for a FECRT with an EPG $\geq 150$. Based on these findings, only first grazing season females were sampled in the dairy goat flocks in 2009. The mean EPG in young females in 2009 was $140( \pm 113)$ and eight $(61.5 \%)$ out of 13 sampled flocks qualified for the FECRT. In total, 13 dairy goat flocks fulfilled the criteria of an EPG of $\geq 150$ prior to the treatment (Table 1). Thus, for the entire survey, a similar proportion of all available sheep and goat flocks were tested for AR in each county (Table 1).

Mean EPG $( \pm \mathrm{SD})$ in the randomly sampled sheep flocks in 2008 and goat flocks in 2008-2009 was $498( \pm 592)$ and

Table 1 Number and percentage of sheep and goat flocks in each tested county and in Norway

\begin{tabular}{|c|c|c|c|c|c|}
\hline \multirow[t]{2}{*}{ Area } & \multirow[t]{2}{*}{ County } & \multicolumn{2}{|c|}{ No. of flocks } & \multicolumn{2}{|c|}{ No. of tested flocks $(\%)$} \\
\hline & & Sheep & Goat & Sheep & Goat \\
\hline \multirow[t]{3}{*}{ Coastal } & Rogaland & 2,682 & 13 & $16(0.6)$ & \\
\hline & Hordaland & 2,012 & 35 & $8(0.4)$ & \\
\hline & Sogn og Fjordane & 1,717 & 35 & & $3(8.6)$ \\
\hline \multirow[t]{3}{*}{ Inland } & Hedmark & 710 & 23 & $5(0.7)$ & $1(4.3)$ \\
\hline & Oppland & 1,351 & 40 & $3(0.2)$ & $2(5)$ \\
\hline & Sør-Trøndelag & 743 & & $4(0.5)$ & \\
\hline \multirow[t]{2}{*}{ Northern } & Nordland & 1,078 & 31 & $3(0.3)$ & $3(9.7)$ \\
\hline & Troms & 588 & 108 & $11(1.9)$ & $4(3.7)$ \\
\hline Norway & & 14,751 & 409 & $48(0.3)$ & $13(3.2)$ \\
\hline
\end{tabular}


$316( \pm 199)$, respectively. In the non-randomly selected sheep flocks sampled in 2009 , the mean EPG $( \pm$ SD) was $394( \pm 197)$.

Teladorsagia/Trichostrongylus (T/T) larvae were present in all investigated sheep and goat flocks (Tables 2, 3, and 4). Larvae identified as Haemonchus (Ha) were found in the pretreatment coprocultures from 17 (35.4\%) of the 48 sheep flocks examined (Tables 2 and 3), but only in two (15.4\%) of the 13 goat flocks (Table 4). L3 of Oesophagostomum/ Chabertia were only encountered at a very low frequency, whereas no Cooperia larvae were found in any flock.

\section{Sheep flocks}

\section{Random sampling}

The FECR after treatment with ivermectin was $100 \%$ in all 19 flocks (data not shown). In the groups dewormed with albendazole, two (flocks 2 and 7) of 19 flocks (10.5\%) had an FECR post-treatment fulfilling the criteria of BZ resistance, i.e., with an FECR of $78 \%$ and $85 \%$, respectively (Table 2). One flock (flock 6) had suspected resistance with an FECR of $96 \%$ and a lower limit of the $95 \%$ CI of $72 \%$ (Table 2). Another flock (flock 9) had a FECR of $98 \%$ but a lower limit of the $95 \%$ CI of $92 \%$, and not fulfilling the criteria to be determined as resistant or suspected resistance. All four flocks with less than 100\% FECR were located in the coastal areas of Rogaland (flocks 2, 6, and 7) and Hordaland (flock 9) counties (Fig. 1). Teladorsagia/ Trichostrongylus larvae were identified in the posttreatment coproculture in one flock (flock 7), whereas Haemonchus was the predominant larval type mixed with Teladorsagia/Trichostrongylus in the other flock (flock 2). In the remaining two flocks with an FECR below $100 \%$ (flocks 6 and 9), all larvae were of Haemonchus-type (Table 3).

\section{Non-random sampling}

ML resistant gastrointestinal nematodes were not detected in the 29 surveyed sheep flocks (data not shown). In contrast, the mean FECR after BZ treatment was on average $92.7 \%$ (CI 86.9-98.7) and ranged from $29 \%$ to $100 \%$ (Table 3). AR to $\mathrm{BZ}$ was recorded in nine flocks $(31.0 \%)$, and they were all located in the coastal area. When restricting the area to Rogaland County, eight flocks (flock 6-12) out of ten (80\%) showed BZ resistance. Two additional flocks located in Rogaland (flock 5) and Hordaland (flock 14) showed results indicating an SR status.

Regarding the nematode genera involved in the nine flocks where resistance was observed, three situations were recorded (Table 3). In five flocks (flocks 5, 6, 8, 9, and 16), $100 \%$ of the L3 in the post-treatment coprocultures were of the Teladorsagia/Trichostrongylus-type. Two flocks (flocks
Table 2 Results of the FECRT in randomly selected sheep flocks treated with albendazole $(n=19)$

Pre- and post-treatment fecal egg counts (mean $\mathrm{EPG} \pm \mathrm{SD}$ ) from the BZ-treated group, percentages of fecal egg count reduction (with $95 \%$ confidence interval), status ( $S$ susceptibility, $S R$ suspected resistance, $R$ resistance), and coproculture results pre- and post-treatment (L3 type in \%)

$R$ Rogaland, $H$ Hordaland, $O$ Oppland, $H M$ Hedmark, $N$ Nordland, $T$ Troms

T/T Teladorsagia/Trichostrongylus, pre-treatment: $n=19$, post-treatment: $n=2 ; \mathrm{Oe} / \mathrm{Ch}$ Oesophagostomum/Chabertia, pre-treatment: $n=2$, post-treatment: $n=0$;

Ha Haemonchus, pre-treatment: $n=5$, post-treatment: $n=3$. No Cooperia larvae were seen

\begin{tabular}{|c|c|c|c|c|c|c|c|c|c|c|}
\hline \multirow[t]{2}{*}{$\begin{array}{l}\text { Flock } \\
\text { no. }\end{array}$} & \multirow[t]{2}{*}{ County } & \multicolumn{2}{|c|}{$\begin{array}{l}\text { Pre-treatment } \\
\text { FEC }\end{array}$} & \multicolumn{2}{|c|}{$\begin{array}{l}\text { Post-treatment } \\
\text { FEC }\end{array}$} & \multirow[t]{2}{*}{$\begin{array}{l}\text { FECR } \\
(\mathrm{Cl})\end{array}$} & \multirow[t]{2}{*}{ Status } & \multicolumn{3}{|c|}{$\begin{array}{l}\text { Coproculture } \\
\text { (pre-/post-treatment) }\end{array}$} \\
\hline & & EPG & $\pm \mathrm{SD}$ & EPG & $\pm \mathrm{SD}$ & & & $\mathrm{T} / \mathrm{T}$ & $\mathrm{Oe} / \mathrm{Ch}$ & $\mathrm{Ha}$ \\
\hline 1 & $\mathrm{R}$ & 165 & 155 & 0 & & 100 & $\mathrm{~S}$ & $100 / 0$ & $0 / 0$ & $0 / 0$ \\
\hline 2 & $\mathrm{R}$ & 2,869 & 1,860 & 427 & 518 & $85(66-94)$ & $\mathbf{R}$ & $67 / 28$ & $0 / 0$ & $33 / 72$ \\
\hline 3 & $\mathrm{R}$ & 445 & 357 & 0 & & 100 & $\mathrm{~S}$ & $100 / 0$ & $0 / 0$ & $0 / 0$ \\
\hline 4 & $\mathrm{R}$ & 480 & 312 & 0 & & 100 & $\mathrm{~S}$ & $88 / 0$ & $0 / 0$ & $12 / 0$ \\
\hline 6 & $\mathrm{R}$ & 608 & 765 & 25 & 69 & $96(72-99)$ & SR & $80 / 0$ & $0 / 0$ & $20 / 100$ \\
\hline 7 & $\mathrm{R}$ & 342 & 227 & 75 & 180 & $76(27-92)$ & $\mathbf{R}$ & $92 / 100$ & $0 / 0$ & $8 / 0$ \\
\hline 8 & $\mathrm{H}$ & 350 & 328 & 0 & & 100 & $\mathrm{~S}$ & $100 / 0$ & $0 / 0$ & $0 / 0$ \\
\hline 9 & $\mathrm{H}$ & 633 & 582 & 19 & 24 & 98(92-99) & $\mathrm{S}$ & $65 / 0$ & $0 / 0$ & $35 / 100$ \\
\hline 12 & $\mathrm{O}$ & 240 & 407 & 0 & & 100 & $\mathrm{~S}$ & $100 / 0$ & $0 / 0$ & $0 / 0$ \\
\hline 13 & $\mathrm{O}$ & 150 & 119 & 0 & & 100 & $\mathrm{~S}$ & $100 / 0$ & $0 / 0$ & $0 / 0$ \\
\hline 15 & $\mathrm{O}$ & 171 & 144 & 0 & & 100 & $\mathrm{~S}$ & $100 / 0$ & $0 / 0$ & $0 / 0$ \\
\hline 18 & $\mathrm{HM}$ & 158 & 79 & 0 & & 100 & $\mathrm{~S}$ & $100 / 0$ & $0 / 0$ & $0 / 0$ \\
\hline 21 & $\mathrm{~N}$ & 425 & 320 & 0 & & 100 & $\mathrm{~S}$ & $100 / 0$ & $0 / 0$ & $0 / 0$ \\
\hline 22 & $\mathrm{~N}$ & 283 & 161 & 0 & & 100 & $\mathrm{~S}$ & $93 / 0$ & $7 / 0$ & $0 / 0$ \\
\hline 23 & $\mathrm{~N}$ & 158 & 313 & 0 & & 100 & $\mathrm{~S}$ & $100 / 0$ & $0 / 0$ & $0 / 0$ \\
\hline 24 & $\mathrm{~T}$ & 525 & 448 & 0 & & 100 & $\mathrm{~S}$ & $100 / 0$ & $0 / 0$ & $0 / 0$ \\
\hline 25 & $\mathrm{~T}$ & 282 & 266 & 0 & & 100 & $\mathrm{~S}$ & $100 / 0$ & $0 / 0$ & $0 / 0$ \\
\hline 26 & $\mathrm{~T}$ & 273 & 371 & 0 & & 100 & $\mathrm{~S}$ & $98 / 0$ & $2 / 0$ & $0 / 0$ \\
\hline 27 & $\mathrm{~T}$ & 900 & 1,178 & 0 & & 100 & $\mathrm{~S}$ & $100 / 0$ & $0 / 0$ & $0 / 0$ \\
\hline
\end{tabular}


Table 3 Results of the FECRT in non-randomly selected sheep flocks treated with albendazole $(n=29)$

\begin{tabular}{|c|c|c|c|c|c|c|c|c|c|c|}
\hline \multirow[t]{2}{*}{ Flock no. } & \multirow[t]{2}{*}{ County } & \multicolumn{2}{|c|}{ Pre-treatment FEC } & \multicolumn{2}{|c|}{ Post-treatment FEC } & \multirow[t]{2}{*}{ FECR $(\mathrm{Cl})$} & \multirow[t]{2}{*}{ Status } & \multicolumn{3}{|c|}{ Coproculture (pre-/post-treatment) } \\
\hline & & EPG & $\pm \mathrm{SD}$ & EPG & $\pm \mathrm{SD}$ & & & $\mathrm{T} / \mathrm{T}$ & $\mathrm{Oe} / \mathrm{Ch}$ & $\mathrm{Ha}$ \\
\hline 2 & $\mathrm{R}$ & 363 & 296 & 0 & & 100 & $\mathrm{~S}$ & $88 / 0$ & $0 / 0$ & $12 / 0$ \\
\hline 4 & $\mathrm{R}$ & 392 & 379 & 0 & & 100 & $\mathrm{~S}$ & $100 / 0$ & $0 / 0$ & $0 / 0$ \\
\hline 5 & $\mathrm{R}$ & 310 & 260 & 15 & 23 & $94(87-99)$ & $\mathbf{R}$ & $85 / 100$ & $0 / 0$ & $15 / 0$ \\
\hline 6 & $\mathrm{R}$ & 382 & 259 & 164 & 98 & $29(0-62)$ & $\mathbf{R}$ & $98 / 100$ & $0 / 0$ & $2 / 0$ \\
\hline 7 & $\mathrm{R}$ & 938 & 740 & 165 & 216 & 75 (57-91) & $\mathbf{R}$ & $82 / 35$ & $0 / 0$ & $18 / 65$ \\
\hline 8 & $\mathrm{R}$ & 400 & 280 & 59 & 141 & $92(85-98)$ & $\mathbf{R}$ & $76 / 100$ & $4 / 0$ & $20 / 0$ \\
\hline 9 & $\mathrm{R}$ & 210 & 102 & 45 & 61 & 75 (55-95) & $\mathbf{R}$ & $92 / 100$ & $0 / 0$ & $8 / 0$ \\
\hline 10 & $\mathrm{R}$ & 373 & 274 & 96 & 152 & $61(19-90)$ & $\mathbf{R}$ & $76 / 0$ & $8 / 0$ & $16 / 100$ \\
\hline 11 & $\mathrm{R}$ & 550 & 810 & 180 & 546 & $90(80-98)$ & $\mathbf{R}$ & $83 / 0$ & $0 / 0$ & $17 / 100$ \\
\hline 12 & $\mathrm{R}$ & 1,000 & 1,346 & 100 & 138 & 89 (79-97) & $\mathbf{R}$ & $79 / 66$ & $0 / 0$ & $21 / 34$ \\
\hline 13 & $\mathrm{H}$ & 423 & 922 & 0 & & 100 & $\mathrm{~S}$ & $100 / 0$ & $0 / 0$ & $0 / 0$ \\
\hline 14 & $\mathrm{H}$ & 531 & 352 & 19 & 42 & 96 (89-99) & SR & $95 / 0$ & $0 / 0$ & $5 / 100$ \\
\hline 15 & $\mathrm{H}$ & 330 & 273 & 0 & & 100 & $\mathrm{~S}$ & $100 / 0$ & $0 / 0$ & $0 / 0$ \\
\hline 16 & $\mathrm{H}$ & 293 & 145 & 29 & 52 & $90(81-98)$ & $\mathbf{R}$ & $98 / 100$ & $2 / 0$ & $0 / 0$ \\
\hline 17 & HM & 394 & 298 & 0 & & 100 & $\mathrm{~S}$ & $100 / 0$ & $0 / 0$ & $0 / 0$ \\
\hline 18 & HM & 273 & 339 & 0 & & 100 & $\mathrm{~S}$ & $100 / 0$ & $0 / 0$ & $0 / 0$ \\
\hline 19 & $\mathrm{HM}$ & 650 & 503 & 0 & & 100 & $\mathrm{~S}$ & $87 / 0$ & $0 / 0$ & $13 / 0$ \\
\hline 20 & $\mathrm{HM}$ & 157 & 155 & 0 & & 100 & $\mathrm{~S}$ & $100 / 0$ & $0 / 0$ & $0 / 0$ \\
\hline 21 & ST & 425 & 403 & 0 & & 100 & $\mathrm{~S}$ & $100 / 0$ & $0 / 0$ & $0 / 0$ \\
\hline 22 & ST & 423 & 285 & 0 & & 100 & $\mathrm{~S}$ & $100 / 0$ & $0 / 0$ & $0 / 0$ \\
\hline 23 & ST & 285 & 110 & 0 & & 100 & $\mathrm{~S}$ & $100 / 0$ & $0 / 0$ & $0 / 0$ \\
\hline 24 & ST & 558 & 593 & 0 & & 100 & $\mathrm{~S}$ & $66 / 0$ & $14 / 0$ & $20 / 0$ \\
\hline 25 & $\mathrm{~T}$ & 297 & 253 & 0 & & 100 & $\mathrm{~S}$ & $100 / 0$ & $0 / 0$ & $0 / 0$ \\
\hline 26 & $\mathrm{~T}$ & 313 & 241 & 0 & & 100 & $\mathrm{~S}$ & $100 / 0$ & $0 / 0$ & $0 / 0$ \\
\hline 27 & $\mathrm{~T}$ & 546 & 783 & 0 & & 100 & $\mathrm{~S}$ & $100 / 0$ & $0 / 0$ & $0 / 0$ \\
\hline 28 & $\mathrm{~T}$ & 257 & 274 & 0 & & 100 & $\mathrm{~S}$ & $100 / 0$ & $0 / 0$ & $0 / 0$ \\
\hline 29 & $\mathrm{~T}$ & 217 & 335 & 0 & & 100 & $\mathrm{~S}$ & $100 / 0$ & $0 / 0$ & $0 / 0$ \\
\hline 30 & $\mathrm{~T}$ & 165 & 171 & 0 & & 100 & $\mathrm{~S}$ & $100 / 0$ & $0 / 0$ & $0 / 0$ \\
\hline 32 & $\mathrm{~T}$ & 333 & 364 & 0 & & 100 & $\mathrm{~S}$ & $100 / 0$ & $0 / 0$ & $0 / 0$ \\
\hline
\end{tabular}

Pre- and post-treatment fecal egg counts (mean $\mathrm{EPG} \pm \mathrm{SD}$ ) from the BZ-treated group, percentages of fecal egg count reduction (with $95 \%$ confidence interval), status ( $S$ susceptibility, $S R$ suspected resistance, $R$ resistance), and coproculture results pre- and post-treatment (larval type in \%)

$R$ Rogaland, $H$ Hordaland, $H M$ Hedmark, ST Sor-Trondelag, $T$ Troms

T/T Teladorsagia/Trichostrongylus, pre-treatment: $n=100$, post-treatment: $n=6$; Oe/Ch Oesophagostomum/Chabertia, pre-treatment: $n=4$, posttreatment: $n=0$; Ha Haemonchus, pre-treatment: $n=12$, post-treatment: $n=5$. No Cooperia larvae were seen

10 and 11) had $100 \%$ of Haemonchus-type and in the remaining two flocks (flock 7 and 12), a mixture of all genera was observed. These two last flocks also had the highest EPG pre-treatment levels (Table 3).

The relationship between the occurrence of AR and various putative risk factors for its development in the studied sheep flocks has been summarized in Table 5 .

\section{Dairy goat flocks}

All surveyed goat flocks were fully susceptible to MLs. On the other hand, one flock (flock 4) in Hedmark County showed apparent resistance to BZ with an FECR of $92 \%$ (95\% CI: 65-98\%) (Table 4). However, this result is questionable since only two out of 12 animals were shedding eggs at post-treatment (data not shown).

\section{Discussion}

It is of great concern that $80 \%$ of the non-randomly surveyed sheep flocks in Rogaland County showed BZ resistance. However, the geographical limitation of AR to this specific region gives the opportunity to control the spread of 
Table 4 Results of the FECRT in the 13 randomly selected goat flocks treated with albendazole $(n=13)$

\begin{tabular}{|c|c|c|c|c|c|c|c|c|c|c|}
\hline \multirow[t]{2}{*}{ Flock no. } & \multirow[t]{2}{*}{ County } & \multicolumn{2}{|c|}{ Pre-treatment FEC } & \multicolumn{2}{|c|}{ Post-treatment FEC } & \multirow[t]{2}{*}{ FECR $(\mathrm{Cl})$} & \multirow[t]{2}{*}{ Status } & \multicolumn{3}{|c|}{ Coproculture (pre-/ post-treatment) } \\
\hline & & EPG & $\pm \mathrm{SD}$ & EPG & $\pm \mathrm{SD}$ & & & $\mathrm{T} / \mathrm{T}$ & $\mathrm{Oe} / \mathrm{Ch}$ & $\mathrm{Ha}$ \\
\hline 4 & HM & 158 & 79 & 17 & 30 & $92(65-98)$ & $\mathbf{R}$ & $100 / 100$ & $0 / 0$ & $0 / 0$ \\
\hline 11 & $\mathrm{O}$ & 150 & 119 & 0 & & 100 & $\mathrm{~S}$ & $100 / 0$ & $0 / 0$ & $0 / 0$ \\
\hline 13 & $\mathrm{O}$ & 171 & 144 & 0 & & 100 & $\mathrm{~S}$ & $100 / 0$ & $0 / 0$ & $0 / 0$ \\
\hline 14 & $\mathrm{SF}$ & 208 & 129 & 0 & & 100 & $\mathrm{~S}$ & $96 / 0$ & $4 / 0$ & $0 / 0$ \\
\hline 15 & $\mathrm{SF}$ & 300 & 212 & 0 & & 100 & $\mathrm{~S}$ & $82 / 0$ & $14 / 0$ & $4 / 0$ \\
\hline 19 & $\mathrm{SF}$ & 271 & 202 & 0 & & 100 & $\mathrm{~S}$ & $98 / 0$ & $0 / 0$ & $2 / 0$ \\
\hline 7 & $\mathrm{~T}$ & 425 & 320 & 0 & & 100 & $\mathrm{~S}$ & $100 / 0$ & $0 / 0$ & $0 / 0$ \\
\hline 8 & $\mathrm{~T}$ & 283 & 161 & 0 & & 100 & $\mathrm{~S}$ & $100 / 0$ & $0 / 0$ & $0 / 0$ \\
\hline 9 & $\mathrm{~T}$ & 158 & 313 & 0 & & 100 & $\mathrm{~S}$ & $100 / 0$ & $0 / 0$ & $0 / 0$ \\
\hline 24 & $\mathrm{~T}$ & 525 & 448 & 0 & & 100 & $\mathrm{~S}$ & $95 / 0$ & $5 / 0$ & $0 / 0$ \\
\hline 25 & $\mathrm{~T}$ & 282 & 266 & 0 & & 100 & $\mathrm{~S}$ & $98 / 0$ & $2 / 0$ & $0 / 0$ \\
\hline 26 & $\mathrm{~T}$ & 273 & 371 & 0 & & 100 & $\mathrm{~S}$ & $100 / 0$ & $0 / 0$ & $0 / 0$ \\
\hline 27 & $\mathrm{~T}$ & 900 & 1178 & 0 & & 100 & $\mathrm{~S}$ & $100 / 0$ & $0 / 0$ & $0 / 0$ \\
\hline
\end{tabular}

Pre- and post-treatment fecal egg counts (mean $\mathrm{EPG} \pm \mathrm{SD}$ ), percentages of fecal egg count reduction (with $95 \%$ confidence interval), status $(S$ susceptibility, $S R$ suspected resistance, $R$ resistance), and coproculture results pre- and post-treatment (larval type in \%)

$H M$ Hedmark, $N$ Nordland, $O$ Oppland, $S F$ Sogn og Fjordane, $T$ Troms

T/T Teladorsagia/Trichostrongylus, pre-treatment: $n=13$, post-treatment: $n=1 ;$ Oe/Ch Oesophagostomum/Chabertia, pre-treatment: $n=4$, posttreatment: $n=0$; Ha Haemonchus, pre-treatment: $n=2$, post-treatment: $n=0$. No Cooperia larvae were seen

resistant GIN to other areas of Norway. Not surprisingly, the survey also indicates that including risk factors in the selection of flocks for FECR tests increases the chance of detecting AR.

\section{Levels of anthelmintic resistance}

The present study shows that in certain areas of Norway, high levels of BZ resistance are present in certain sheep flocks. As far as randomly selected flocks are concerned, the prevalence of $\mathrm{BZ}$ resistance of $11 \%$ could be considered to be on a rather low level (Table 2). However, both resistant flocks and one of the two flocks showing a reduced susceptibility were located in Rogaland County. Among the nonrandomly selected flocks, eight of the nine flocks with AR nematodes were situated in the southwestern part of Norway
(Rogaland County). In Rogaland County, 33\% and 80\% AR flocks were detected by random and non-random sampling, respectively.

All sheep flocks with BZ resistance or suspected resistance against BZs were from Rogaland and Hordaland counties, where $21 \%$ and $10 \%$, respectively, of the total sheep production in Norway occur (Statistics Norway 2008). Hence, the findings of the present survey are of particular concern.

The efficacy of the BZ albendazole varied, with an average FECR of $92.7 \%$ in the non-random flocks. The very low efficacy in some flocks may indicate that BZ resistance has been present for some time but has not previously been acknowledged. In contrast, there was still no evidence for a reduction in the efficacy of ivermectin.

Table 5 Number of flocks, annual drench frequency, dose-and-move practice, and stocking rate in the different counties grouped according to AR status

\begin{tabular}{llllll}
\hline AR & Area & Number of flocks & Annual drench frequency mean \pm SD (range) & Dose-and-move (\%) & Stocking rate (\%) $(>6$ animals/ha) \\
\hline Yes & $\begin{array}{l}\text { Coastal } \\
\text { Inland }\end{array}$ & 14 & $5.4 \mathrm{a} \pm 1.0(4-8)$ & 78.6 & 57.1 \\
& & & & 50 \\
No & Corthern & & & 87.5 & 66.6 \\
& Inland & 12 & $3.4 \mathrm{c} \pm 1.1(2-5)$ & 50 & 63.6
\end{tabular}

Drenching frequency a was significantly different (Mann-Whitney, $p<0.05)$ from $b$. Drenching frequency a was not significantly different $($ MannWhitney, $p<0.05$ ) from $\mathrm{c}$. 
The differences in the prevalence of AR among different counties and regions are considered to be real, since a similar proportion of the total number of sheep and goat flocks was tested, $0.2-1.9 \%$ and $3.7-9.7 \%$ of all sheep and goat flocks, respectively (Table 1 ). However, altogether, only $0.4 \%$ of all sheep flocks and $3.2 \%$ of all goat flocks in Norway were tested in this survey. Hence, this study may not accurately reflect the actual situation concerning AR in Norway, since it would have been necessary to test a larger proportion of the flocks to be able to reveal the presence of AR.

Validation of material and methods

The FECRT is still considered as the most practical and direct way of detecting nematodes resistant to $\mathrm{BZ}$ and $\mathrm{ML}$ in sheep and goats (Cabaret 2004), although it has a low sensitivity, being able to detect AR only in populations where more than $25 \%$ of the worms are resistant (Martin et al. 1989). Aside from slaughter trials, FECRT is currently the only reliable test for the detection of ML resistance. An alternative, more sensitive FECRT protocol has been suggested, which is based on half the dose of ML (Coles et al. 2006), but the presence of mixed natural infections may complicate the interpretation of this test.

Another possible critical issue is the occurrence of low excretion of nematode eggs and the large confidence intervals sometimes associated with the FECR calculations. Techniques with a high-analytic sensitivity are preferred for monitoring drug efficacy in populations with low fecal egg excretion (Levecke et al. 2011). In this study, we used individually based estimations of efficacy using a bootstrap procedure in order to both minimize the influence of single high shedding animals and generate more accurate reduction and confidence interval values (Cabaret and Berrag 2004). In such a situation with a low level of infection, Bentousi et al. (2007) used a different protocol based on repeated anthelmintic treatments of animals on day 0 and 10 with fecal sampling on day 20 and calculations as mentioned previously. In addition, other AR detection methods such as the egg hatch test and the larval development tests have so far only been validated for BZ and LEV, not for ML (Coles et al. 2006). Similarly, PCR-based tests in a field situation are still limited to the detection of BZ resistance in Haemonchus (Höglund et al. 2009) and requires further development before being used as a universal and practical quantitative tool (Coles et al. 2006).

Relationship between AR and potential risk factors

According to Silvestre et al. (2002), the three management factors that have been identified and have contributed to the development of AR in small ruminants are as follows: (a) underdosing in combination with repeated use of anthelmintics, (b) the proportion of parasite stages in refugia at the time of treatment, and (c) the introduction of resistant worms through purchase of animals infected with resistant parasites.

In the present study, the resistant flocks in the coastal area had a significantly higher annual drenching rate of their lambs than the flocks in the inland and northern area where no AR was detected $(p<0.05)$ (Table 5). An extensive use of anthelmintics combined with opportunities for underdosing has been considered as a major risk factor for development of AR (Waller 1994). In the majority of Norwegian sheep flocks, a clear risk for underdosing linked to either inaccurate dose estimation, lack of calibration of the drench gun, or ingestion failure have been recorded (Domke et al. 2011).

Governmental reports from Rogaland County have indicated a reduction in the use of mountain and forest pastures for sheep during the last 10 years (Rogaland Fylkeskommune 2011). This has not been accompanied with a reduction in the number of animals, and this could be interpreted as an intensification of home pasture grazing. Such a managerial shift leads to higher stocking rates, and the pastures being changed to more or less permanent grazing areas, which in itself increases the selection of nematode populations for AR (Waller 1994). This may have contributed to the selection for AR, as it has also been speculated that rangeland act as a refugia for unselected nematode stages on pasture (van Wyk 2001).

The trade of sheep in Norway is regulated by The Norwegian Food Safety Authority (http://mattilsynet.no). Although it is allowed to transport sheep between the counties for grazing, it is against the rule to translocate sheep between farms located in different counties. Animal introduction has been suggested as an important mechanism in the spread of resistance (Alvarez-Sanchez et al. 2006). To control the spread of AR, the restriction on trade of sheep has to be maintained. Moreover, testing flocks for AR before trade or ram exchange could be an additional option to minimize the risk for AR spread both in sheep and goats. Combined with quarantine drenching against GIN, this could decrease the risk of spreading AR nematodes to other flocks. However, quarantine drenching must be considered as a risk factor for AR if the animals are not tested after they leave the quarantine.

Keeping goats and sheep together on the same pasture has been considered to increase the risk for developing AR. However, in the present study none of the resistant sheep flocks had any contact with goats.

Goats

The GIN infections in Norwegian goat flocks is, overall, still on a low level. Only 13 (46\%) of the 28 randomly selected goat flocks had an egg count above 150 EPG prior to deworming. This indicated that the GIN burdens seem to be under 
control in most flocks. As far as first-year grazing goats or kids are concerned, these animals do not always graze at the same pasture as the adult dairy goats on the farm do, and this could explain a low infection level and worm composition compared to sheep where ewes and lambs share the same pasture.

A low drench frequency, normally once a year, combined with low stocking rate and a common use of ivermectin characterizes the worm control management of Norwegian goat flocks (Domke et al. 2011). Most of the Norwegian goat farmers were not aware of the need to use an increased dose for goats compared to the given sheep dose rate (Leine, personal communication). Due to this, a risk for systematic underdosing of Norwegian goats seems to have been the situation although only one questionable case of AR has been identified so far. However, a limited use of anthelmintics in combination with low stocking rates seem to have prevented the development of AR despite the risk of underdosing of Norwegian goats. In France, however, a low number of treatments per year and exclusive use of a given anthelmintic family, have resulted in AR emergence in many dairy goat flocks (Chartier et al. 2001). This strongly suggests that the contribution of the resistant worms surviving the anthelmintic treatment to the subsequent generation, including the concept of refugia, is probably more important than the number of anthelmintic treatments itself, and this can be considered as a key factor that determines resistance emergence (Silvestre et al. 2002).

Norway compared to other Nordic countries

In Denmark, resistance against all substance classes (i.e. BZ, LEV, and ML) has been detected in both sheep and goats (Maingi et al. 1996a, b), whereas no data are available for goats, and only BZ-resistant GIN have been described from sheep in Sweden (Höglund et al. 2009). No systematic studies regarding AR have been performed in Finland or Iceland (Oksanen and Skírnisson, personal communication).

Teladorsagia and Trichostrongylus were the dominant genera regarding AR in Denmark (Maingi et al. 1996a, b), whereas Haemonchus was the main genera in Sweden (Höglund et al. 2009). It is of great concern that Haemonchus, both in Norway and Sweden, seems to be the main resistant genus considering its clinical potential. However, AR against a single drug and single species suggests that the resistance is likely on its beginning (Cringoli et al. 2007), and that control measures to limit its development and spreading can be implemented.

\section{Conclusion}

The rather unique Norwegian combination of rangeland grazing with a low stocking rate under subarctic conditions seems to limit the level of GIN infection and the need for anthelmintic treatments. Despite a reduced possibility of having nematodes in refugia at pasture level under subarctic climatic conditions, the situation concerning AR in the inland and northern area is promising compared to the southern coastal area. In the latter, the high number of anthelmintic treatments, a high stocking rate, and the practicing of the doseand-move strategy have to be considered as potential risks factors for the emergence of AR, which should be communicated to the farmers. These risk factors and the farm status concerning AR should be implemented in the governmental trade regulation of sheep in Norway. It is of great concern that seven of the eight surveyed non-random selected flocks that showed BZ resistance where located in Rogaland County. Development of new strategies and recommendations to control the AR situation in this county is therefore urgently needed to avoid a spread of resistant nematodes into other regions. On the other hand, the present results indicate that the Norwegian goat farming management does not represent a risk for the development of AR.

Acknowledgements We thank the Norwegian Goat Health Service, Animalia by the Norwegian Sheep Health Service, the Norwegian School of Veterinary Science, and the Norwegian Research Council for financial support. Thanks to all the farmers and local veterinary practitioners for participating. Also thanks to the laboratory staff at the Norwegian School of Veterinary Science, Sandnes (Høyland Field Station), especially to Marianne Haga, for handling the samples.

Open Access This article is distributed under the terms of the Creative Commons Attribution Noncommercial License which permits any noncommercial use, distribution, and reproduction in any medium, provided the original author(s) and source are credited.

\section{References}

Alvarez-Sanchez MA, Perez-Garcia J, Cruz-Rojo MA, Rojo-Vázquez FA (2006) Anthelmintic resistance in Trichostrongylid nematodes of sheep farms in Northwest Spain. Parasitol Res 99:78-83

Bartley DJ, Jackson E, Johnston K et al (2003) A survey of anthelmintic resistant nematode parasites in Scottish sheep flocks. Vet Parasitol 117:61-71. doi:10.1016/j.vetpar.2003.07.023

Bauer C (2001) Multispecific resistance of Trichostrongyles to benzimidazoles in a goat herd in Germany. Dtsch Tierarztl Wochenschr 8:49-50

Bentounsi B, Attir B, Meradi S et al (2007) Repeated treatment faecal egg counts to identify gastrointestinal nematode resistance in a context of low-level infection of sheep on farms in eastern Algeria. Vet Parasitol 144:104-110

Bogan J, Benoite E, Delatour P (1987) Pharmacokinetics of oxfendazole in goats: a comparison with sheep. J Vet Pharmacol Ther 10:305-309. doi:10.1111/j.1365-2885.1987.tb00106.x

Cabaret J (2004) Efficacy evaluation of anthelmintics: which methods to use in the field? Parassitologia 46:241-243

Cabaret J, Berrag B (2004) Faecal egg count reduction test for assessing anthelmintic efficacy: average versus individually based estimations. Vet Parasitol 121:105-113. doi:16/j.vetpar.2004.01.020 
Cernanska D, Varady M, Corba J (2006) A survey on anthelmintic resistance in nematode parasites of sheep in the Slovak Republic. Vet Parasitol 135:39-45

Chartier C, Pors I, Hubert J et al (1998) Prevalence of anthelminticresistant nematodes in sheep and goats in Western France. Small Rumin Res 29:33-41. doi:10.1016/S0921-4488(97)00116-8

Chartier C, Etter E, Pors I, Alvinerie M (1999) Activity of eprinomectin in goats against experimental infections with Haemonchus contortus, Teladorsagia circumcincta and Trichostrongylus colubriformis. Vet Rec 144:99-100. doi:10.1136/vr.144.4.99

Chartier C, Soubirac F, Pors I et al (2001) Prevalence of anthelmintic resistance in gastrointestinal nematodes of dairy goats under extensive management conditions in southwestern France. J Helminthol 75:325-330. doi:10.1017/S0022149X01000506

Coles GC (1997) Nematode control practices and anthelmintic resistance on British sheep farms. Vet Rec 141:91-93. doi:10.1136/vr.141.4.91

Coles GC, Bauer C, Borgsteede FHM et al (1992) World Association for the Advancement of Veterinary Parasitology (W.A.A.V.P.) methods for the detection of anthelmintic resistance in nematodes of veterinary importance. Vet Parasitol 44:35-44. doi:10.1016/ 0304-4017(92)90141-U

Coles GC, Warner AK, Best JR (1996) Triple resistant Ostertagia from angora goats. Vet Rec 139:299-300

Coles GC, Jackson F, Pomroy WE et al (2006) The detection of anthelmintic resistance in nematodes of veterinary importance. Vet Parasitol 136:167-185

Cringoli G, Veneziano V, Rinaldi L et al (2007) Resistance of trichostrongyles to benzimidazoles in Italy: a first report in a goat farm with multiple and repeated introductions. Parasitol Res 101:577-581

Domke A, Chartier C, Gjerde B et al (2011) Worm control practice against gastro-intestinal parasites in Norwegian sheep and goat flocks. Acta Vet Scand 53:29. doi:10.1186/1751-0147-53-29

Hennessy DR, Alvinerie M (2002) Pharmacokinetics of the macrocyclic lactones: conventional wisdom and new paradigms In: Vercruysse J., Rew R.S. (eds) Macrocyclic lactones and antiparasitic activity. CAB International pp 97-123

Hennessy DR, Sangster NC, Steel JW, Collins GH (1993) Comparative pharmacokinetic behaviour of albendazole in sheep and goats. Int J Parasitol 23:321-325. doi:16/0020-7519(93)90006-K

Höglund J, Gustafsson K, Ljungström B-L et al (2009) Anthelmintic resistance in Swedish sheep flocks based on a comparison of the results from the faecal egg count reduction test and resistant allele frequencies of the beta-tubulin gene. Vet Parasitol 161:60-68. doi:10.1016/j.vetpar.2008.12.001

Hoste H, Chartier C, Frileux YL (2002) Control of gastrointestinal parasitism with nematodes in dairy goats by treating the host category at risk. Vet Res 33:15. doi:10.1051/vetres:2002037

Levecke B, Rinaldi L et al (2011) Monitoring drug efficacy against gastrointestinal nematodes when faecal egg counts are low: do the analytic sensitivity and the formula matter? Parasitol Res 109:953-957

Maingi N, Bjørn H, Thamsborg SM et al (1996a) A survey of anthelmintic resistance in nematode parasites of goats in Denmark. Vet Parasitol 66:53-66

Maingi N, Bjørn H, Thamsborg SM et al (1996b) Worm control practices on sheep farms in Denmark and implications for the development of anthelmintic resistance. Vet Parasitol 66:3952

Martin PJ, Anderson N, Jarrett RG (1989) Detecting benzimidazole resistance with faecal egg count reduction tests and in vitro assays. Aust Vet J 66:236-240

Ministry of Agriculture, Fisheries and Food (1986) Manual of veterinary parasitological laboratory techniques. 3 rd ed. Her Majesty's Stationary Office (HMSO), London

Paraud C, Kulo A, Pors I, Chartier C (2009) Resistance of goat nematodes to multiple anthelmintics on a farm in France. Vet Rec 164:563-564

Rogaland fylkeskommune (2011) Beite og kulturlandskap - for folk og fe. Rogaland fylkeskommune. http://www.regjeringen.no/upload/ LMD/Fylkesnytt/vedlegg/Beiteheftet.pdf

Sangster NC, Steel JW, Collins GH, Hennessy DR (1993) Comparative kinetic disposition of oxfendazole in sheep and goats before and during infection with Haemonchus contortus and Trichostrongylus colubriformis. J Vet Pharmacol Therap $16: 245-253$

Sargison N, Scott P, Jackson F (2001) Multiple anthelmintic resistance in sheep. Vet Rec 149:778-779

Short CR, Barker SA, Hsieh LC et al (1987) Disposition of fenbendazole in the goat. Am J Vet Res 48:811-815

Silvestre A, Leignel V, Berrag B, Gasnier N, Humbert JF, Chartier C, Cabaret J (2002) Sheep and goat nematode resistance to anthelmintics; pro and cons among breeding management factors. Vet Res 33:465-480

Statistics Norway (2008) Agriculture Statistics. http://www.ssb.no/ jordbruk en/. Accessed 19 July 2011.

Traversa D, Paoletti B, Otranto D, Miller J (2007) First report of multiple drug resistance in trichostrongyles affecting sheep under field conditions in Italy. Parasitol Res 101:1713-1716

Ulvund M, Malmei T, Oma P (1994) Undersøkelse av benzimidazol resistens hos sauenematoder i Rogaland. Småfenytt 2:11-23

van Wyk JA (2001) Refugia — overlooked as perhaps the most potent factor concerning the development of anthelmintic resistance. Onderstepoort J Vet Res 68:55-67

Vatn S, Myklebust O, Stuen S (2005) Resistente parasitter hos sau? Resultat fra et lite prosjekt i Rogaland. Praksisnytt 3:12-14

Waller PJ (1994) The development of anthelmintic resistance in ruminant livestock. Acta Trop 56:233-243. doi:10.1016/0001-706X (94)90065-5 